\title{
Strength Prediction of Aluminum-Stainless Steel-Pulsed TIG Welding-Brazing Joints with RSM and ANN
}

\author{
Huan He $\cdot$ Chunli Yang $\cdot$ Zhe Chen $\cdot$ Sanbao Lin $\cdot$ Chenglei Fan
}

Received: 6 September 2013/Revised: 20 January 2014/Published online: 7 August 2014

(C) The Chinese Society for Metals and Springer-Verlag Berlin Heidelberg 2014

\begin{abstract}
Pulsed TIG welding-brazing process was applied to join aluminum with stainless steel dissimilar metals. Major parameters that affect the joint property significantly were identified as pulsed peak current, base current, pulse on time, and frequency by pre-experiments. A sample was established according to central composite design. Based on the sample, response surface methodology (RSM) and artificial neural networks (ANN) were employed to predict the tensile strength of the joints separately. With RSM, a significant and rational mathematical model was established to predict the joint strength. With ANN, a modified back-propagation algorithm consisting of one input layer with four neurons, one hidden layer with eight neurons, and one output layer with one neuron was trained for predicting the strength. Compared with RSM, average relative prediction error of ANN was $<10 \%$ and it obtained more stable and precise results.
\end{abstract}

KEY WORDS: Welding-brazing; Aluminum; Stainless steel; Response surface methodology (RSM); Artificial neural networks (ANN); Prediction

\section{Introduction}

Composite structures of the aluminum and steel, which own excellent comprehensive mechanical properties and light weight, play a crucial role in modern manufacture. However, joining of the two dissimilar metals is an ever existing challenge. Leading to potential safety risks, a high level residual stress is prone to exist in the joints due to the evident differences in the thermal properties of the aluminum and steel. What is more, massive brittle intermetallic compound (IMC) resulting from diminutive reciprocal solid solubility of dissimilar metals and high driving force of IMC reaction would decrease the joints' mechanical properties significantly $[1,2]$.

Available online at http://link.springer.com/journal/40195

H. He $\cdot$ C. Yang $\cdot$ Z. Chen $\cdot$ S. Lin $(\bowtie) \cdot$ C. Fan

State Key Laboratory of Advanced Welding and Joining, Harbin Institute of Technology, Harbin 150001, China

e-mail: sblin@hit.edu.cn
Taking above problems into account, numerous researchers in this field endeavor to obtain hybrid structures of $\mathrm{Al} / \mathrm{Steel}$ with satisfactory quality with multiple welding techniques [3-11]. Compared with solid state joining and traditional brazing, welding-brazing technique avoids strict requirements of work pieces' shape and size and attracts much attention in joining aluminum and steel dissimilar metals. Moreover, the process of arc weldingbrazing is fairly economical with no need for special welding surroundings, i.e., vacuum, when it comes to the choice of heat source of welding-brazing compared with electron beam and laser [5, 7].

As for normal continuous current TIG welding-brazing, the impetuous arc burns the flux continuously, which leads to a very short time of flux activity. Without enough flux activity time, the molten aluminum filler cannot spread adequately on the surface of steel. While in the case of pulsed TIG welding-brazing process, the basic current will contribute to protracting the activity time of melting flux after the action of transient pulsed peak current. So, there exists enough activity time for melting filler to spread 
Table 1 Chemical compositions of base metal and filler metal (wt\%)

\begin{tabular}{llllllllllll}
\hline Material & $\mathrm{C}$ & $\mathrm{Mn}$ & $\mathrm{Mg}$ & $\mathrm{Si}$ & $\mathrm{Cu}$ & $\mathrm{Zn}$ & $\mathrm{Ti}$ & $\mathrm{Ni}$ & $\mathrm{Cr}$ & $\mathrm{Fe}$ & $\mathrm{Al}$ \\
\hline SUS321 & 0.12 & 2 & - & 1 & - & - & 0.2 & $8-10$ & $17-19$ & $\mathrm{Bal}$ \\
5A06 & - & $0.5-0.8$ & $5.8-6.8$ & 0.4 & 0.1 & 0.2 & 0.1 & - & - & 0.4 \\
ER1100 & - & 0.05 & - & $x$ & $0.05-0.2$ & 0.1 & - & - & - & $0.95-x$ & Bal. \\
\hline
\end{tabular}

Note total content of $\mathrm{Si}$ and $\mathrm{Fe}$ in ER1100 is $0.95 \mathrm{wt} \%$

sufficiently on the surface of base metal, hence, the weld appearance tends to be formed unanimously and stably. Moreover, as it is clarified in many references [12-15], the addition of pulsed current enhances the mechanical properties of joints by refining the microstructure of weld seam and contributes to excellent appearance with the impact action of arc force.

It is evident that owing a series of advantages, pulsed TIG welding-brazing technique avoids the different kinds of shortages of other welding techniques discussed above in the domain of the joining of aluminum and steel, which suggests that the technique, once optimized its process parameters, will enjoy an momentous application value in the manufacture of high quality $\mathrm{Al} / \mathrm{Steel}$ hybrid structures.

However, the welding process of the technique is extremely complex and there exist so many parameters such as frequency of $\mathrm{AC}$, balance, pulsed peak current, base current, duty cycle constant, and frequency of pulsed current. The relationship between the property of joints and the process parameters is indeed critical in order to optimize the process of the technique but nonlinear and complicated, which leads to a great difficulty in analysis of parameters and prediction of property of joints. In accord with the references, artificial neural networks (ANNs), which imitate the brain of humankind to establish the computational model and possess the great approximation ability of nonlinear function, have been employed in such kind of high level nonlinear systems [16-24]. Besides, some analysis methodologies based on the combination of mathematics and statistics are utilized in welding research [25-27], i.e., optimizing of process with response surface methodology (RMS).

In this study, both RSM and ANN were employed to predict the mechanical property of the aluminum/stainless steel pulse TIG welding-brazing joints and the prediction results as well as errors of the two methods were compared and discussed.

\section{Materials and Methods}

The base metals employed in this study are 5A06 aluminum alloy and SUS321 stainless steel plates with dimension of $100 \mathrm{~mm} \times 50 \mathrm{~mm} \times 3 \mathrm{~mm}$. The filler metals used is ER1100 commercially pure aluminum welding wire with a diameter of $1.6 \mathrm{~mm}$. The chemical compositions of the base and filler metal are reported in Table 1.

A single- $\mathrm{V}$ groove was prepared in the plates, with a bevel angle of $45^{\circ}$ in both steel and aluminum alloy side. And then base materials were polished with sander and cleaned up by acetone before the welding process as preparation. The neighborhood of steel grooves was precoated subsequently with a layer of special flux in $0.2-0.5$ $\mathrm{mm}$ thickness. The main ingredients of the flux include $50 \mathrm{wt} \%$ noncorrosive Nocolok flux $\left(\mathrm{KAlF}_{4}\right.$ and $\mathrm{K}_{3} \mathrm{AlF}_{6}$ eutectic) and $50 \mathrm{wt} \%$ aluminum powder and trace binder potassium sodium tartrate.

Aluminum-steel butt TIG welding-brazing experiments were carried out using Miller Dynasty 350 welding equipment. The welding parameters were $\mathrm{AC}$ square wave of $100 \mathrm{~Hz}$ and $50 \% \mathrm{AC}$ balance, pulse current, arc length of 3.0-4.0 mm, welding speed of $150 \mathrm{~mm} / \mathrm{min}$, and argon gas flow rate of $8-10 \mathrm{~L} / \mathrm{min}$. Tensile tests were conducted by INSTRON-5569 testing machine, with loading speed of $0.5 \mathrm{~mm} / \mathrm{min}$. All tests were repeated at least three times.

\section{Results and Discussion}

\subsection{Design of Experiment}

Central composite design (CCD) was utilized in this research due to its various merits such as unanimous, rotary and typical samples, and relatively fewer experiments which provided much information still. The procedures are detailed as follows:

(1) Identifying the major process of the parameters among the multiple parameters of the pulsed TIG welding-brazing technique and the corresponding working limits of each parameter by the massive preexperiments with variable-controlling approach.

(2) Designing the test samples with the working limits of major parameters on the basis of rules of CCD.

(3) Conducting the joining experiments according to the parameters combinations of the samples designed above and testing the tensile strength of the weldments. 


\subsection{Sample Establishment}

The experiments were conducted following the procedures above and the major parameters were identified as pulsed peak current, base current, duty cycle constant, and frequency of the pulsed current of which the working limits are listed in Table 2 . The other fixed parameters of the technique are listed in Table 3. The unanimous sample by CCD with the results of tensile tests is presented in Table 4 .

\subsection{Prediction by RSM}

A second-order mathematical model was established for the samples above in order to employ the RSM to analyze the relationship between the parameters and the property of the joints. Regarding the tensile strength as fitted value, we set the second-order regression equation as follows by least-square method using the Design-Expert software:

$$
\begin{aligned}
\sigma= & -3730.25407+36.50751 \times I_{\mathrm{p}}+21.79765 \\
& \times t_{\mathrm{p}}+24.46683 \times I_{\mathrm{b}}-5.00840 \times f \\
& -0.13698 \times I_{\mathrm{p}} \times t_{\mathrm{p}}-0.12062 \times I_{\mathrm{p}} \times I_{\mathrm{b}} \\
& +0.032568 \times I_{\mathrm{p}} \times f-0.12058 \times t_{\mathrm{p}} \times I_{\mathrm{b}} \\
& -0.082283 \times I_{\mathrm{p}}^{2}+0.10487 \times t_{\mathrm{p}}^{2}
\end{aligned}
$$

where $\sigma$ is the tensile strength $(\mathrm{MPa}), I_{\mathrm{p}}$ is the pulsed peak current $(\mathrm{A}), I_{\mathrm{b}}$ is the pulsed basic current $(\mathrm{A}), t_{\mathrm{p}}$ is the duty cycle constant $(\%)$, and $f$ is the frequency $(\mathrm{Hz})$.

And then the analysis of variance was employed to identify the significance of the model, as listed in Table 5. It is obvious that the model in the study is significant while the lack of fit is unremarkable by checking the probability, which means the model we established is able to fit the sample.

Besides, the analysis of the residuals was applied to testify the rationality of the established model, and the normal plot of the residuals and the plot of residuals vs. predicted tensile strengths are shown separately in Figs. 1 and 2. It is obvious that residuals present normal distribution, which indicates that the model is rational.

RSM was employed to predict the tensile strength by the established mathematic model. The prediction results of a test sample of 5 sets of parameters combinations which were not from the CCD sample within the range of working limits are listed in Table 6. It is obvious that some of results show a high prediction precision and we can use the model to predict the tensile strength of Al/Steel weldingbrazing joints within some ranges, although it fails to achieve excellent stability [26].
Table 2 Major parameters and corresponding working limits

\begin{tabular}{llll}
\hline $\begin{array}{l}\text { Peak } \\
\text { current (A) }\end{array}$ & $\begin{array}{l}\text { Pulse on } \\
\text { time (\%) }\end{array}$ & $\begin{array}{l}\text { Basic } \\
\text { current (A) }\end{array}$ & $\begin{array}{l}\text { Frequency of pulsed } \\
\text { current }(\mathrm{Hz})\end{array}$ \\
\hline $145-155$ & $35-45$ & $55-65$ & $28-76$ \\
\hline
\end{tabular}

Table 3 Fixed parameters

\begin{tabular}{lll}
\hline Welding speed $(\mathrm{mm} / \mathrm{min})$ & Balance $(\%)$ & Frequency of $\mathrm{AC}(\mathrm{Hz})$ \\
\hline 180 & 50 & 100 \\
\hline
\end{tabular}

Table 4 Parameters and tensile strengths for samples of central composite design

\begin{tabular}{llllll}
\hline Number & $\begin{array}{l}\text { Peak } \\
\text { current } \\
\text { (A) }\end{array}$ & $\begin{array}{l}\text { Pulse on } \\
\text { time }(\%)\end{array}$ & $\begin{array}{l}\text { Basic } \\
\text { current } \\
(\mathrm{A})\end{array}$ & $\begin{array}{l}\text { Frequency of } \\
\text { pulsed current } \\
(\mathrm{Hz})\end{array}$ & $\begin{array}{l}\text { Tensile } \\
\text { strength } \\
\text { (MPa) }\end{array}$ \\
\hline No. 1 & 145.00 & 35.00 & 55.00 & 76.00 & 156.58 \\
No. 2 & 150.00 & 40.00 & 60.00 & 52.00 & 198.30 \\
No. 3 & 150.00 & 40.00 & 60.00 & 52.00 & 204.69 \\
No. 4 & 145.00 & 35.00 & 55.00 & 28.00 & 163.68 \\
No. 5 & 145.00 & 35.00 & 65.00 & 76.00 & 186.93 \\
No. 6 & 155.00 & 45.00 & 55.00 & 76.00 & 211.06 \\
No. 7 & 155.00 & 45.00 & 65.00 & 28.00 & 213.59 \\
No. 8 & 145.00 & 35.00 & 65.00 & 28.00 & 197.86 \\
No. 9 & 150.00 & 40.00 & 60.00 & 4.00 & 213.55 \\
No. 10 & 145.00 & 45.00 & 55.00 & 76.00 & 195.54 \\
No. 11 & 140.00 & 40.00 & 60.00 & 52.00 & 188.34 \\
No. 12 & 150.00 & 30.00 & 60.00 & 52.00 & 194.90 \\
No. 13 & 150.00 & 40.00 & 60.00 & 52.00 & 188.90 \\
No. 14 & 150.00 & 40.00 & 60.00 & 52.00 & 207.69 \\
No. 15 & 150.00 & 50.00 & 60.00 & 52.00 & 234.02 \\
No. 16 & 160.00 & 40.00 & 60.00 & 52.00 & 203.15 \\
No. 17 & 155.00 & 45.00 & 65.00 & 76.00 & 216.29 \\
No. 18 & 150.00 & 40.00 & 50.00 & 52.00 & 187.26 \\
No. 19 & 145.00 & 45.00 & 65.00 & 28.00 & 222.22 \\
No. 20 & 155.00 & 45.00 & 55.00 & 28.00 & 202.53 \\
No. 21 & 155.00 & 35.00 & 65.00 & 28.00 & 198.73 \\
No. 22 & 150.00 & 40.00 & 70.00 & 52.00 & 212.64 \\
No. 23 & 150.00 & 40.00 & 60.00 & 100.00 & 190.96 \\
No. 24 & 155.00 & 35.00 & 55.00 & 76.00 & 188.69 \\
No. 25 & 155.00 & 35.00 & 65.00 & 76.00 & 197.68 \\
No. 26 & 145.00 & 45.00 & 55.00 & 28.00 & 209.70 \\
No. 27 & 150.00 & 40.00 & 60.00 & 52.00 & 201.50 \\
No. 28 & 145.00 & 45.00 & 65.00 & 76.00 & 210.24 \\
No. 29 & 155.00 & 35.00 & 55.00 & 28.00 & 180.51 \\
No. 31 & 150.00 & 40.00 & 60.00 & 52.00 & 206.19 \\
\hline & 150.00 & 40.00 & 60.00 & 52.00 & 196.00 \\
\hline
\end{tabular}


Table 5 Analysis of variance

\begin{tabular}{lrrrrr}
\hline Item & $\begin{array}{l}\text { Sum of } \\
\text { squares }\end{array}$ & $\begin{array}{l}\text { Degree of } \\
\text { freedom }\end{array}$ & $\begin{array}{l}\text { Mean } \\
\text { square }\end{array}$ & \multicolumn{1}{l}{$F$} & Probability \\
\hline Model & $6,586.67$ & 10 & 658.67 & 17.29 & $<0.0001$ \\
$I_{\mathrm{p}}$ & 383.60 & 1 & 383.60 & 10.07 & 0.0048 \\
$t_{\mathrm{p}}$ & $3,474.02$ & 1 & $3,474.02$ & 91.18 & $<0.0001$ \\
$I_{\mathrm{b}}$ & $1,441.66$ & 1 & $1,441.66$ & 37.84 & $<0.0001$ \\
$f$ & 209.98 & 1 & 209.98 & 5.51 & 0.0293 \\
$I_{\mathrm{p}} \times t_{\mathrm{p}}$ & 187.62 & 1 & 187.62 & 4.92 & 0.0382 \\
$I_{\mathrm{p}} \times I_{\mathrm{b}}$ & 145.50 & 1 & 145.50 & 3.82 & 0.0648 \\
$I_{\mathrm{p}} \times f$ & 244.38 & 1 & 244.38 & 6.41 & 0.0198 \\
$I_{\mathrm{b}} \times t_{\mathrm{p}}$ & 145.38 & 1 & 145.38 & 3.82 & 0.0649 \\
$I_{\mathrm{p}}^{2}$ & 123.53 & 1 & 123.53 & 3.24 & 0.0869 \\
$t_{\mathrm{p}}^{2}$ & 200.65 & 1 & 200.65 & 5.27 & 0.0327 \\
Residual & 761.98 & 20 & 38.10 & - & - \\
Lack of fit & 506.31 & 14 & 36.17 & 0.85 & 0.6282 \\
Pure error & 255.67 & 6 & 42.61 & - & - \\
\hline
\end{tabular}

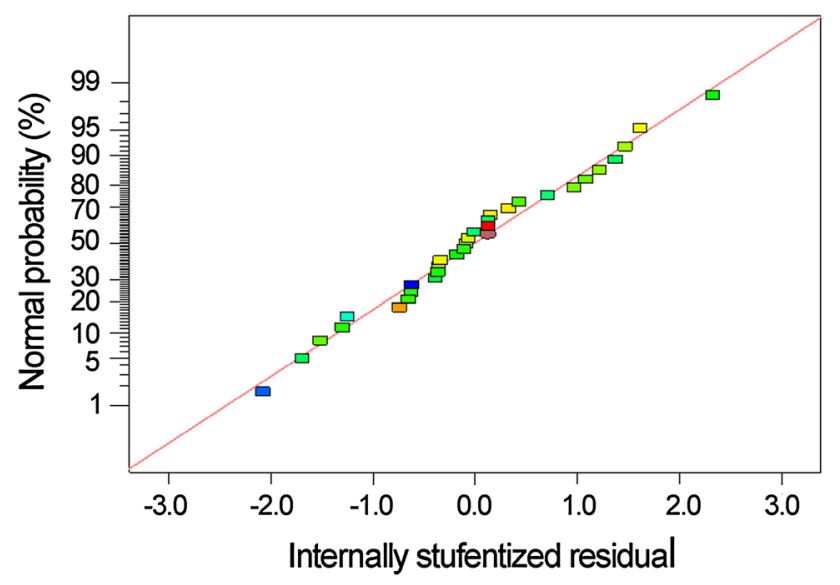

Fig. 1 Normal plot of residuals

\subsection{Prediction by ANN}

On the basis of brains of humankind, ANN is an advanced information processing system that imitates the function of neural networks by computational technology and applied in engineering broadly $[18,19]$. A modified back-propagation (BP) algorithm was employed in this study, and appropriate parameters of the networks are listed in Table 7 by trial and errors. The structure of this BP networks is shown in Fig. 3. There were four neurons in the input layer which corresponded to four process parameters, i.e., peak current, basic current, pulse on time, and frequency. And the number of neuron in output layer was just one which stands for tensile strength. By trial and error, the

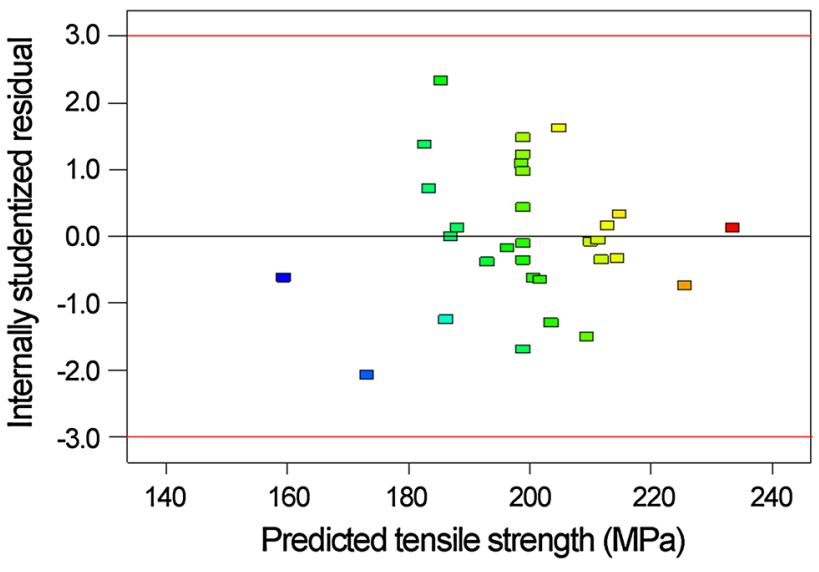

Fig. 2 Plot of residuals versus predicted tensile strengths

mean square error reached its minimum when there was one hidden layer which contained eight neurons in the networks, as presented in Fig. 4. And the learning rate combined with the momentum factor contributed to a proper rate of convergence and high precision.

The training sample for the networks derived from the CCD above which just met the demand in unanimity and symmetry. Then, Matlab software was utilized to train the model for predicting the tensile strength of Al/Steel-pulsed TIG welding-brazing joints. Figure 5 presents the trend diagram of changes of training error. It is clear that the training results convergent at around 5786 epochs [20].

Then, the ANN after training was used to predict the tensile strength with the same test sample for RSM in order to compare the ability to predict the two methods, and the results of prediction are presented in Table 8 . It is evident that ANN within this research possesses excellent generalization ability and the average relative error of prediction for tensile strength corresponding to "unfamiliar sample" was $<10 \%$. Besides, the overall errors showed a stationary distribution.

\subsection{Comparison of RSM with ANN}

Within the research, both RSM and ANN were employed to predict the tensile strength of joints, and the results of the predictions for the same test sample by the two methods were compared, as shown in Fig. 6. It is clear that the relative prediction error of ANN is extremely smaller and more stable than that of RSM, while part of the sample could be predicted precisely by RSM [21].

However, it takes a long time to establish an eligible ANN including adjusting, training, testing, and selecting the multiple functions with massive parameters. Besides, numerous times of training may be indispensible in order to achieve high precision. Compared with ANN with large 
Table 6 Results of prediction by RSM and the relative errors

\begin{tabular}{lllllllr}
\hline Number & $\begin{array}{l}\text { Peak current } \\
(\mathrm{A})\end{array}$ & $\begin{array}{l}\text { Pulse on time } \\
(\%)\end{array}$ & $\begin{array}{l}\text { Basic current } \\
(\mathrm{A})\end{array}$ & $\begin{array}{l}\text { Frequency } \\
(\mathrm{Hz})\end{array}$ & $\begin{array}{l}\text { Predicted tensile } \\
\text { strength (MPa) }\end{array}$ & $\begin{array}{l}\text { Experimental tensile } \\
\text { strength (MPa) }\end{array}$ & $\begin{array}{l}\text { Relative error } \\
(\%)\end{array}$ \\
\hline No. 1 & 140 & 40 & 56 & 100 & 150.16 & 195.47 & 23.18 \\
No. 2 & 140 & 40 & 65 & 25 & 208.63 & 211.20 & 1.22 \\
No. 3 & 140 & 50 & 60 & 4 & 252.51 & 228.36 & 10.58 \\
No. 4 & 160 & 50 & 54 & 100 & 234.44 & 198.35 & 18.20 \\
No. 5 & 150 & 50 & 70 & 52 & 236.94 & 238.29 & 0.56 \\
\hline
\end{tabular}

Table 7 Determined parameters of the networks

\begin{tabular}{ll}
\hline Parameters & Value \\
\hline Number of input layer neurons & 4 \\
Number of hidden layer neurons & 8 \\
Number of output layer neurons & 1 \\
Rate of learning & 0.4 \\
Momentum factor & 0.5 \\
Algorithm & BP with momentum term
\end{tabular}

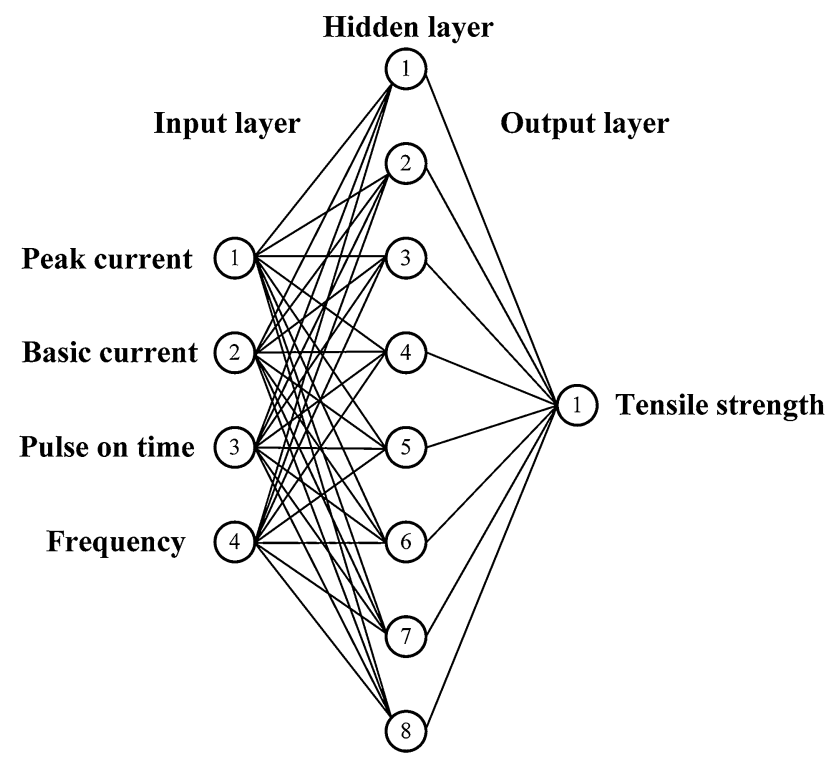

Fig. 3 Schematic of the ANN structure

amount of preparation, RSM works it out effectively and rapidly in establishing the mathematic model, analysis of variance, and predicting the object with a certain range of accuracy.

What is more, the relationship between process parameters and tensile strength cannot be inferred directly by the established networks without more complicated and auxiliary algorithm. But we can achieve this readily through RSM that does not only provide significant mathematic

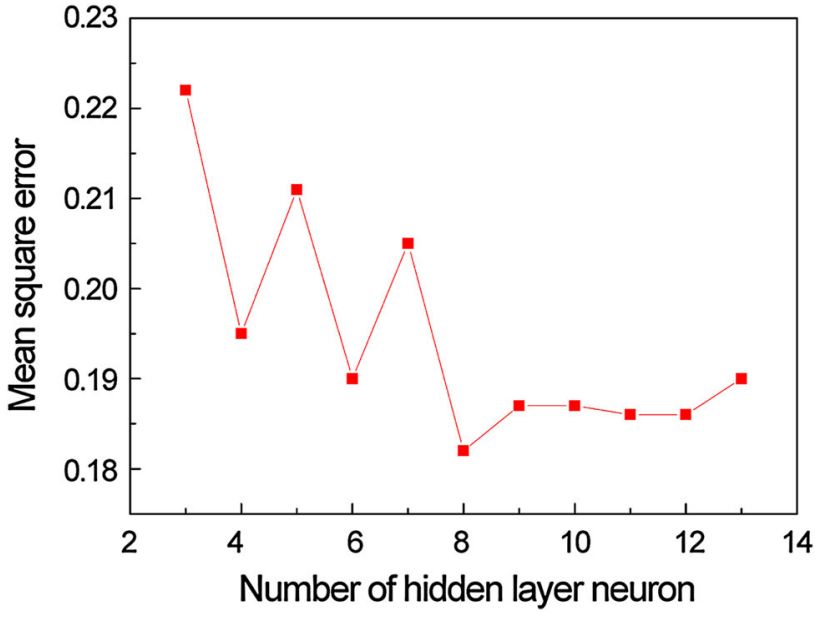

Fig. 4 Relationship between mean square error and number of hidden layer neurons

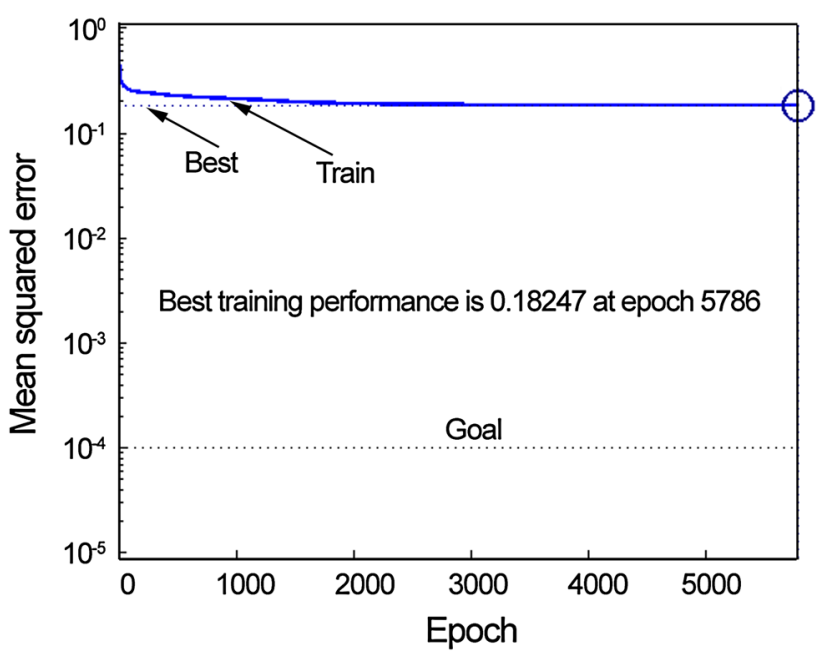

Fig. 5 Trend diagram of training error change

model, clear response surface plots, and contours for the tensile strength from the model, but also offer the information about interactions of parameters and influence of 
Table 8 Results of prediction by ANN and relative errors

\begin{tabular}{llllllll}
\hline Number & $\begin{array}{l}\text { Peak current } \\
(\mathrm{A})\end{array}$ & $\begin{array}{l}\text { Pulse on time } \\
(\%)\end{array}$ & $\begin{array}{l}\text { Basic current } \\
(\mathrm{A})\end{array}$ & $\begin{array}{l}\text { Frequency } \\
(\mathrm{Hz})\end{array}$ & $\begin{array}{l}\text { Predicted value } \\
(\mathrm{MPa})\end{array}$ & $\begin{array}{l}\text { Experimental value } \\
(\mathrm{MPa})\end{array}$ & $\begin{array}{l}\text { Relative error } \\
(\%)\end{array}$ \\
\hline No. 1 & 140 & 40 & 56 & 100 & 181.98 & 195.47 & 6.9 \\
No. 2 & 140 & 40 & 65 & 25 & 213.16 & 211.20 & 0.9 \\
No. 3 & 140 & 50 & 60 & 4 & 216.28 & 228.36 & 5.2 \\
No. 4 & 160 & 50 & 54 & 100 & 209.79 & 198.35 & 5.5 \\
No. 5 & 150 & 50 & 70 & 52 & 216.30 & 238.29 & 9.2 \\
\hline
\end{tabular}

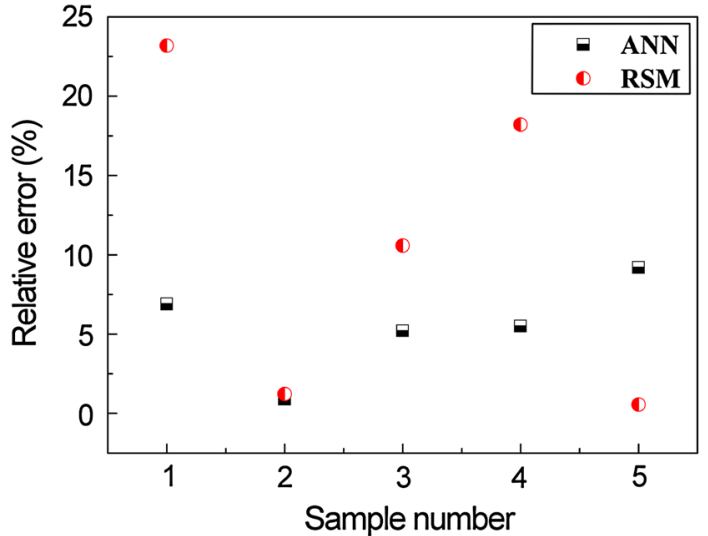

Fig. 6 Comparison of relative prediction errors between ANN and RSM

parameters on tensile strength, which makes it easier to optimize the parameters.

\section{Conclusions}

The major parameters of the pulsed TIG welding-brazing processing of aluminum to stainless steel dissimilar metals were identified as pulsed peak current, base current, pulse on time, and frequency of pulsed current. Based on the sample designed by CCD, both RSM and ANN were applied successfully in predicting the tensile strength of the joints. For RSM, a significant and rational mathematical model was established for predicting the joint strength. And for ANN, a modified BP algorithm consisting of one input layer with four neurons, one hidden layer with eight neurons, and one output layer with one neuron was well trained to realize the prediction. The ANN model is fairy capable to predict the tensile strength of joints within the training range and more accurate than RSM, and the average relative prediction error is $<10 \%$.

Acknowledgments This work was financially supported by the National Natural Science Foundation of China (No. 50874033).

\section{References}

[1] K. Bouche, F. Barbier, A. Coulet, Mater. Sci. Eng. A 249, 167 (1998)

[2] J. Regina, J. DuPont, A. Marder, Weld. J. 86, 170s (2007)

[3] E. Taban, J.E. Gould, J.C. Lippold, Mater. Des. 31, 2305 (2010)

[4] A. Fuji, Sci. Technol. Weld. Jt. 9, 83 (2004)

[5] S. Mei, M. Gao, J. Yan, C. Zhang, G. Li, X. Zeng, Sci. Technol. Weld. Jt. 18, 293 (2013)

[6] T. Aizawa, M. Kashani, K. Okagawa, Weld. J. 86, 119s (2007)

[7] M. Rathod, M. Kutsuna, Weld. J. 83, 16s (2004)

[8] H.P. Yu, Z.D. Xu, C.F. Li, Z.X. Zhao, Acta Metall. Sin. 47, 197 (2011) (in Chinese)

[9] G.L. Qin, Y.H. Su, S.J. Wang, Acta Metall. Sin. 48, 1018 (2012) (in Chinese)

[10] S.B. Lin, J.L. Song, C.L. Yang, G.C. Ma, Acta Metall. Sin. 45, 1211 (2009) (in Chinese)

[11] H. Dong, C. Liao, Acta Metall. Sin. (Engl. Lett.) 26, 143 (2013)

[12] A. Kumar, S. Sundarrajan, Int. J. Adv. Manuf. Technol. 42, 118 (2009)

[13] A. Liu, X. Tang, F. Lu, Int. J. Adv. Manuf. Technol. 59, 1 (2012)

[14] R. Manti, D. Dwivedi, A. Agarwal, Int. J. Adv. Manuf. Technol. 36, 263 (2008)

[15] B. Qi, M. Yang, B. Cong, F. Liu, Int. J. Adv. Manuf. Technol. 66, 1545 (2013)

[16] L. Carrino, U. Natale, L. Nele, M. Sabatini, L. Sorrentino, Int. J. Adv. Manuf. Technol. 32, 459 (2007)

[17] B. Chen, J. Wang, S. Chen, Int. J. Adv. Manuf. Technol. 48, 83 (2010)

[18] S. Ghosal, S. Chaki, Int. J. Adv. Manuf. Technol. 47, 1149 (2010)

[19] I.N. Tansel, M. Demetgul, H. Okuyucu, A. Yapici, Int. J. Adv. Manuf. Technol. 48, 95 (2010)

[20] P. Kalyanasundaram, C. Mukhopadhyay, C. Rajagopalan, B. Raj, Sci. Technol. Weld. Jt. 10, 7 (2005)

[21] I.S. Kim, S.-H. Lee, P.K. Yarlagadda, Sci. Technol. Weld. Jt. 8, 347 (2003)

[22] S.W. Campbell, A. Galloway, N. McPherson, Weld. J. 91, 174s (2011)

[23] M. Lightfoot, G. Bruce, N. McPherson, K. Woods, Weld. J. 84, 23s (2005)

[24] S. Mishra, T. Debroy, Weld. J. 85, 231s (2006)

[25] S. Elangovan, K. Anand, K. Prakasan, Int. J. Adv. Manuf. Technol. 63, 561 (2012)

[26] R. Karthikeyan, V. Balasubramanian, Int. J. Adv. Manuf. Technol. 51, 173 (2010)

[27] M. Khan, L. Romoli, M. Fiaschi, G. Dini, F. Sarri, Int. J. Adv. Manuf. Technol. 62, 587 (2012) 